(c) 2020, The Authors. Published by FASS Inc. and Elsevier Inc. on behalf of the American Dairy Science Association ${ }^{\circledR}$.

This is an open access article under the CC BY-NC-ND license (http://creativecommons.org/licenses/by-nc-nd/4.0/).

\title{
Prevalence and characterization of Staphylococcus aureus isolates from subclinical bovine mastitis in southern Xinjiang, China
}

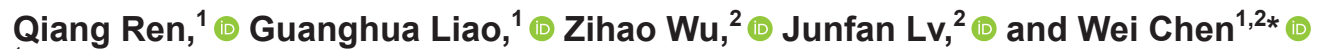 \\ ${ }^{1}$ Key Laboratory of Protection and Utilization of Biological Resources in Tarim Basin of Xinjiang Production and Construction Corps, \\ College of Life Sciences, Tarim University, Alar 86-843300, China \\ ${ }^{2}$ College of Animal Sciences, Key Laboratory of Tarim Animal Husbandy and Science Technology of Xinjiang Production and Construction Corps, \\ Tarim University, Alar 86-843300, China
}

\section{ABSTRACT}

Staphylococcus aureus is one of the major pathogens causing mastitis in dairy herds. The colonization of dairy cows and subsequent contamination of raw milk by $S$. aureus, especially strains exhibiting multidrug resistance and biofilm-forming and toxin-producing abilities, remains an important issue for both dairy farmers and public health. In this study, we investigated the prevalence, antimicrobial susceptibility, biofilm formation, and genetic diversity of $S$. aureus from subclinical bovine mastitis in dairy farms located in southern Xinjiang, China. Sixty-five isolates from 84 subclinical mastitic milk samples were identified as $S$. aureus. The resistance rates to penicillin, erythromycin, clindamycin, tetracycline, gentamicin, linezolid, rifampicin, quinupudin-dafupudin, ciprofloxacin, norfloxacin, and chloramphenicol were 58.5, 44.6, 40.0, 18.5, $12.3,10.8,9.2,6.2,4.6,4.6$, and $1.5 \%$, respectively. All isolates were susceptible to cefoxitin, sulfamethoxazoletrimethoprim, and vancomycin. Isolates from farm A showed a significantly higher resistance rate to tetracycline $(16.9 \%)$ than those from farm B $(1.5 \%)$. The most frequently detected virulence factors were hla $(96.9 \%$, $63 / 65)$ and $h l b(100.0 \%, 65 / 65)$. The percentage rates of the staphylococcal enterotoxin genes sea, sec, sed, seg, seh, sei, and sej in $S$. aureus isolates were 4.6, 33.8, $27.7,3.1,41.5,41.5$, and $7.7 \%$, respectively. The percentage rate of the sec gene in isolates from farm B $(30.8 \%)$ was significantly higher than that of farm A $(3.1 \%)$. The percentage rates of the tsst and pvl genes in S. aureus isolates were 26.2 and $40.0 \%$. The percentage rate of the $p v l$ gene in isolates from farm B $(32.3 \%)$ was significantly higher than that of farm A (7.7\%). The adhesion molecules $f n b A, f n b B, c l f A, c l f B$, and cna were detected in $21(32.3 \%), 23(35.4 \%), 65(100.0 \%)$, $65(100.0 \%)$, and $65(100.0 \%)$ isolates, respectively. The

Received August 7, 2019.

Accepted November 28, 2019.

*Corresponding author: 379497687@qq.com percentage rates of the icaA, sarA, tcaR, ccp, luxS, and $\operatorname{sig} B$ genes in $S$. aureus isolates were $69.2,100.0,86.2$, $95.4,84.6$, and $100.0 \%$, respectively. The $f n b B$ and $i c a A$ genes were more frequently detected in isolates from farm A (29.2 and $40.0 \%$, respectively) than those from farm B (6.2 and $29.2 \%$, respectively). The luxS gene was more often found in isolates from farm B (50.8\%) than those from farm A (33.8\%). Using the microplate method, $61.5,26.2$, and $10.8 \%$ of the isolates showed weak, moderate, and strong biofilm-forming abilities, respectively. Different clonal complex $(\mathrm{CC})$ and spatypes were identified, including CC81, CC398, CC88, CC5405, and CC5406. Importantly, in this study we report for the first time 41 new sequence types (ST) among 44 distinct ST. These results indicated high genetic diversity of $S$. aureus involved in subclinical bovine mastitis in southern Xinjiang, China. The results also showed that $S$. aureus from subclinical bovine mastitis cases in southern Xinjiang, China, were mainly resistant to $\beta$-lactams, erythromycin, and clindamycin. Also, biofilm- and adhesion-related genes, which are increasingly known as important virulence factors in the pathogenesis of $S$. aureus infections, were detected at a high rate. This study could help identify predominant clones and provide surveillance measures to decrease or eliminate $S$. aureus contamination in raw milk of dairy cows with subclinical mastitis.

Key words: Staphylococcus aureus, raw milk, mastitis, antimicrobial resistance, molecular typing

\section{INTRODUCTION}

Staphylococcus aureus is one of the leading pathogens causing mastitis in dairy cows. It is reported that up to $40.0 \%$ of mastitis cases in China and other countries are caused by S. aureus (Kateete et al., 2013; Basanisi et al., 2017; Wang et al., 2018). Dairy cow mastitis is a global challenge, because it impairs animal health and welfare, decreases milk production, and increases health care costs. Thus the economic losses for the dairy industry are considerable (Hertl et al., 2010; Schroeder, 
2012; Wang et al., 2018). More importantly, contaminated raw milk at farm level may lead to subsequent public health problems, giving rise to association of $S$. aureus with food contamination (Jakobsen et al., 2011; Rola et al., 2016; Wang et al., 2018).

Various virulence genes in $S$. aureus encode a wide range of virulence factors, such as toxic shock syndrome toxin-1 (TSST-1), staphylococcus enterotoxins (SE), hemolysins (HL), and Panton-Valentine leukocidin (PVL; Wang et al., 2018). Staphylococcus enterotoxins are considered the major cause of $S$. aureus associated with food poisoning. It is reported that more than $90.0 \%$ of $S$. aureus-related food poisoning outbreaks were attributable to the classic SE encoded by the sea to see genes (Tarekgne et al., 2016). The staphylococcal enterotoxins A and D (SEA and SED) are regarded as the major sources of food poisoning (Sato'o et al., 2014; Arfatahery et al., 2016). The TSST-1 toxin could cause toxic shock syndrome by attenuating the host immune response, and PVL could destroy host leukocytes and result in tissue necrosis (Wang et al., 2018).

Antibiotic therapy is an important measure for controlling bovine mastitis and human infections (Gomes and Henriques, 2016). However, an increasing number of studies report that $S$. aureus exhibits resistance to multiple classes of antimicrobial agents as a response to the selective pressures of antimicrobials (Gomes and Henriques, 2016). Additionally, biofilm formation is frequently associated with chronic and recurrent infections in animals and humans. Biofilm-associated protein (Bap) plays a key role in initial attachment and recruitment of $S$. aureus (Khoramian et al., 2015; Felipe et al., 2017). The icaA gene, found at the ica locus present in S. aureus and in Staphylococcus epidermidis, plays an important role in biofilm production (Aslantaş and Demir, 2016). The icaA gene encodes $N$-acetylglucosaminyltransferase responsible for the $\mathrm{N}$-acetylglucosamine oligomers from UDP- $N$-acetylglucosamine (Arciola et al., 2001; Aslantaş and Demir, 2016). Also, S. aureus possess a diverse of adhesins that play crucial roles in the onset of infection by binding host tissues and are regarded as important virulence factors. Of these adhesins, fibronectin-binding proteins ( $f n b A$ and $f n b B)$, clumping factors (clfA and clfB), and collagen-binding protein (cna) are considered important virulence factors in binding host cells, colonization, and invasion (Haveri et al., 2008; Aslantaş and Demir, 2016). Additionally, S. aureus have a variety of global regulators controlling the production of virulence factors. Staphylococcal accessory regulator $(\operatorname{sar} A)$ is a central regulatory element that is essential for the synthesis of polysaccharide intercellular adhesin (PIA) and biofilm development in this species. Under $i c a$-independent conditions, it is reported that $\operatorname{sig} B$ is critical to biofilm formation in $S$. aureus (Lauderdale et al., 2009).

Molecular epidemiology-based methods are important tools to analyze clonal relatedness and genetic diversity, and to track the dissemination of $S$. aureus infections (Wang et al., 2018). Molecular epidemiologybased methods have reportedly been widely used in animal husbandry, medical care, food safety testing, and other fields (Montanaro et al., 2016; Käppeli et al., 2019; Sun et al., 2019). Multilocus sequence typing (MLST) based on the profiles of alleles at 7 loci of housekeeping genes ( $\operatorname{arc} C$, aroE, glpF, gmk, pta, tpi, and yqiL) and spa-typing based on the variable X-region of the staphylococcal protein A gene (spa) have been used to confirm the highly clonal structure of $S$. aureus (Shopsin et al., 1999). Some research has found that particular $S$. aureus clonal lineages may be prevalent geographically, and exhibit specific antibiotic-resistant and virulence patterns (Hata et al., 2010; Wang et al., 2018). Thus, better knowledge about the genotypes of $S$. aureus isolates involved in dairy cow mastitis might lead to more effective measures to reduce the spread of infection and could be useful to track the sources of infection ( $\mathrm{Li}$ et al., 2017).

The aims of the present study were (1) to study molecular genetic characteristics, (2) to investigate antibiotic susceptibility, (3) to determine the ability of biofilm formation and the related genes, and (4) to search for adhesin-related genes such as cna, fnb, and clf genes and enterotoxin genes in $S$. aureus isolates from subclinical mastitis.

\section{MATERIALS AND METHODS}

\section{Isolation and Identification of S. aureus from Milk}

According to National Mastitis Council (NMC) guidelines, a total of 84 mastitic milk samples were aseptically collected from cows with subclinical mastitis in 2 different farms of southern Xinjiang, China, including farm A (in the Akesu region; herd size $\geq 100$; milking frequency, 2 times per day; $\mathrm{n}=44$ samples) and farm B (in Bayingol Mongolian Autonomous Prefecture; herd size $\geq 100$; milking frequency, 2 times per day; $n$ $=40$ samples). Subclinical bovine mastitis cases were detected using the California Mastitis Test. For milk collection, the udders of cows with subclinical mastitis were cleaned with water and dried. Cotton balls with $75 \%$ ethanol were used to disinfect the surface of the udder. The first few streams of milk were discarded. The collected milk was kept in a sterile tube and transported to the laboratory within $4 \mathrm{~h}$. Milk samples were 
cultured in mannitol salt broth (MSB; Hope Bio, Qingdao, China) and then incubated aerobically at $37^{\circ} \mathrm{C}$ for 24 to $72 \mathrm{~h}$, followed by streaking on Columbia blood agar (CBA; Hope Bio). The plates were incubated at $37^{\circ} \mathrm{C}$ for 24 to $72 \mathrm{~h}$. Primary identification of $S$. aureus was performed by picking the characteristic colonies (large, creamy, and strongly hemolytic on CBA). All these potential $S$. aureus isolates were subcultured to be identified by routine biochemical properties (Atalla et al., 2008). Confirmation of identification was performed by $16 \mathrm{~S}$ rRNA gene sequencing as well as by PCR analysis of the thermonuclease $(n u c)$ gene specific to this species (Brakstad et al., 1992). The retrieved $S$. aureus isolates were kept at $-20^{\circ} \mathrm{C}$ in tryptic soy broth (TSB; Becton Dickinson, Wokingham, UK), containing $20 \%$ volumes of glycerol, for further study.

\section{Antibiotic Susceptibility Testing}

A panel of 14 antimicrobial agents was used to detect the antibiotic susceptibility of all the tested isolates. Tetracycline $(30 \mu \mathrm{g})$, penicillin G $(10 \mathrm{U})$, linezolid $(30 \mu \mathrm{g})$, chloramphenicol $(30 \mu \mathrm{g})$, clindamycin $(2 \mu \mathrm{g})$, ciprofloxacin $(5 \mu \mathrm{g})$, gentamicin $(10 \mu \mathrm{g})$, norfloxacin $(10 \mu \mathrm{g})$, erythromycin $(15 \mu \mathrm{g})$, sulfamethoxazole-trimethoprim $(25 \mu \mathrm{g})$, rifampicin $(5 \mu \mathrm{g})$, and quinupudindafupudin $(15 \mu \mathrm{g})$ were tested via the agar diffusion (Kirby-Bauer) method using Mueller-Hinton agar (Oxoid, Waltham, MA) and commercially available discs (Oxoid) according to Clinical and Laboratory Standards Institute (CLSI) guidelines (CLSI, 2015). Vancomycin susceptibility was tested via broth microdilution, according to the recommendations of the CLSI (CLSI, 2015). Staphylococcus aureus ATCC25923 and S. aureus ATCC29213 were used as quality-control strains.

\section{Detection of MRSA, Virulence, and Biofilm-Related Genes}

A cefoxitin $(30 \mu \mathrm{g})$ disc was used for detecting methicillin-resistant isolates. Staphylococcus aureus ATCC25923 was used as a control. The mecA gene responsibile for methicillin-resistant $S$. aureus (MRSA) was detected by PCR using primers mecA F (5'-AAAATCGATGGTAAAGGTTGGC- $3^{\prime}$ ) and mec $A$ R (5'-AGTTCTGCAGTACCGGATTTGC-3'; Panahi and Saei, 2019).

The genes encoding PVL (lukF; Li et al., 2018), SE (sea, seb, sec, sed, see, seg, seh, sei, and sej; Løvseth A et al., 2004), exfoliative toxin (eta and etb; Li et al., 2018), HL (hla and hlb; Li et al., 2018), TSST (tsst; Løvseth A et al., 2004), adhesion factor ( $f n b A, f n b B$, clfa, clfb, and cna; Zmantar et al., 2008; Klein et al., 2012; Li et al., 2018), and biofilm-related genes (bap, icaA, ccp,
luxS, sarA, sigB, agrC, tcaR; Ciftci et al., 2009) were amplified via PCR.

\section{Biofilm Formation Assay}

Isolates' ability to form biofilm was assessed using a 96-well microtiter plate assay, as previously described (Pratt and Kolter, 1998; Xie et al., 2019). Briefly, cells were diluted 1:100 with fresh TSB broth and cultured at $37^{\circ} \mathrm{C}$ for $24 \mathrm{~h}$ without shaking. Biofilms were stained with crystal violet (Sigma-Aldrich, St. Louis, MO) and dissolved in $95 \%$ ethanol (wt/vol: $0.5 \%$ ). The optical density was determined at $570 \mathrm{~nm}$ in an enzyme-linked immunosorbent assay reader (Bio-Rad, Hercules, CA). A strong biofilm-former, S. epidermidis ATCC35984 was selected as the positive control, and sterile TSB was used as negative control for the biofilm production assays (Xie et al., 2019). These biofilm assays were performed in triplicate including biological duplicates. An $\mathrm{OD}_{570}$ value of 0.13 was applied as the cutoff point to distinguish between biofilm formers and non-biofilm formers [cutoff $(\mathrm{ODc})=$ average OD $+3 \mathrm{SD}$ of negative control]. Biofilm formation was classified as strong $\left(+++; \mathrm{OD}_{570}>0.39\right)$, moderate $\left(++; 0.39>\mathrm{OD}_{570}>\right.$ $0.26)$, weak $\left(+; 0.26>\mathrm{OD}_{570}>0.13\right)$, or negative $(-$; $\left.\mathrm{OD}_{570}<0.13\right)$.

\section{Multilocus Sequence Typing (MLST)}

Multilocus genotyping based on the sequencing of 7 housekeeping genes (arcC, aroE, glpF, gmk, pta, tpi, and yqiL) was performed on all $65 \mathrm{~S}$. aureus isolates (Montanaro et al., 2016). Alleles and sequence type (ST) were assigned according to the $S$. aureus MLST database (https://pubmlst.org/saureus/). The ST were then clustered into clonal complexes (CC) used for the goeBURST algorithm by phyloviz (http://goeBURST .phyloviz.net).

\section{Spa Typing}

The isolates were subjected to PCR amplification for the polymorphic $\mathrm{X}$ region of the spa gene, using the standard primers spa-1113f (5'-TAAAGACGATCCTTCGGTGAGC-3') and spa-1514r (5'-CAGCAGTAGTGCCGTTTGCTT-3'); primers and protocol available on the Ridom Spa Server database (http://www.spaserver .ridom.de/). The purified PCR products of the spa gene were sequenced, and then spa type was deduced using this database. The BURP (Based Upon Repeat Patterns) algorithm analysis was performed using the Ridom StaphType software (Ridom GmbH, Münster, Germany) to cluster related spa types. If a spa repeat did not match any spa types, the sequence of this spa 
Table 1. Prevalence of Staphylococcus aureus from subclinical bovine mastitis in dairy farms located in southern Xinjiang, China

\begin{tabular}{lccc}
\hline Farm & No. of samples & $\begin{array}{c}\text { No. of } S \text {. aureus } \\
\text { isolates }\end{array}$ & $\begin{array}{c}\text { No. of MRSA } \\
\text { isolates }\end{array}$ \\
\hline A & 44 & 30 & 0 \\
B & 40 & 35 & 0 \\
Total & 84 & 65 & 0 \\
\hline${ }^{1}$ MRSA = methicillin-resistant $S$. aureus &
\end{tabular}

was uploaded to the Ridom Spa Server database to assign a new type.

\section{Statistical Analysis}

The chi-squared test was calculated using SPSS 18.0 software (SPSS, Chicago, IL) to analyze the differences in the prevalence, antimicrobial resistance, distribution of virulence or biofilm-producing genes, and biofilm formation ability between the 2 farms. A $P$-value < 0.05 was considered statistically significant.

\section{RESULTS}

\section{Isolation and Identification of S. aureus}

A total of $65 S$. aureus isolates were identified by morphological, biochemical methods and $16 \mathrm{~S}$ rRNA gene sequencing in this study (Table 1). We obtained 30 and $35 \mathrm{~S}$. aureus isolates from samples collected from farms $\mathrm{A}$ and $\mathrm{B}$, respectively. No isolate showed resistance to cefoxitin and harbored the mecA gene (Table 1).

\section{MLST and Spa Typing}

Information on the isolation and identification of MLST and spa types is shown in Table 2. We identified 44 distinct ST within the 65 isolates, including 41 new ST $(93.2 \%, 41 / 44)$. Of 44 ST, 27 ST $(61.4 \%$, $27 / 44$ ) were found in farm A, 24 of which were new ST, and $18 \mathrm{ST}(40.9 \%, 18 / 44)$ were found in farm B, 17 of which were novel. In both farms A and B, ST398 was the same ST. The goeBURST analysis clustered all 44 $\mathrm{ST}$ isolated from subclinical bovine mastitis into $5 \mathrm{CC}$ in farm A, including CC81, CC398, and CC88, and into 3 CC, including CC398, CC5405, and CC5406, in farm B. Of these complexes, CC81 and CC398 were predominant in farm A, and CC5405 and CC5406 were predominant in farm B.

The spa typing discriminated $65 \mathrm{~S}$. aureus isolates into 8 spa types, of which 5 were obtained in farm A and 3 were found in farm B. The most prevalent spa type was t5100 $(40.0 \%, 12 / 30)$ in farm A. In addition, 4 other spa types (t034, t2970, t2592, and t1764) were also detected in isolates from farm A. Isolates from farm B were defined by 3 spa types: $\mathrm{t} 189, \mathrm{t} 571$, and t519. The most predominant spa type was t189 $(57.1 \%$, $20 / 35$ ) in farm B. Based on spa typing, isolates with identical spa types exhibited different ST (Table 2).

\section{Antimicrobial Susceptibility Profiles}

Data on the antimicrobial susceptibility of $65 S$. aureus isolates are shown in Table 3 . All $S$. aureus isolates were susceptible to vancomycin and cefoxitin. Various rates of resistance to penicillin $(58.5 \%, 38 / 65)$, erythromycin $(44.6 \%, 29 / 65)$, clindamycin $(40.0 \%, 26 / 65)$, tetracycline $(18.5 \%, 12 / 65)$, gentamicin $(12.3 \%, 8 / 65)$, linezolid $(10.8 \%, 7 / 65)$, rifampicin $(9.2 \%, 6 / 65)$, quinupudin-dafupudin $(6.2 \%, 4 / 65)$, norfloxacin $(4.6 \%, 3 / 65)$, ciprofloxacin $(4.6 \%, 3 / 65)$, and chloramphenical $(1.5 \%$, $1 / 65)$ were detected in this study. Isolates from farm A showed significantly higher resistance to tetracycline $(16.9 \%)$ than those from farm B $(P<0.05$; Table 4 and Table 5). Of 65 S. aureus isolates, $27(41.5 \%)$ strains showed a multidrug-resistant phenotype (MDR, resistant to 3 or more classes of antimicrobial agents; Table 3; Figure 1).

The resistance profiles of $S$. aureus isolates differed by their CC or spa types (Table 5). Of CC398-t034 isolates, $90 \%$ exhibited the MDR phenotype. We found that CC5406-t519 isolates displayed the highest rates of resistance to erythromycin $(100.0 \%)$ and clindamycin $(91.7 \%)$.

\section{Detection of Virulence Genes}

All isolates harbored at least 1 virulence gene (Table 6; Figure 1). Of the 15 investigated virulence genes (tsst, pvl, eta, etb, hla, hlb, sea, seb, sec, sed, see, seg, seh, sei, and sej), the hlb, hla, pvl, and tsst genes were detected in 65 (100.0\%), $63(96.9 \%), 26(40.0 \%)$, and $17(26.2 \%)$ isolates, respectively (Table 6; Figure 1). Of the 9 investigated enterotoxin genes, seh, sei, sec, sed, sej, sea, and seg were detected in $27(41.5 \%), 27$ $(41.5 \%), 22(33.8 \%), 18(27.7 \%), 5(7.7 \%), 3(4.6 \%)$, and $2(3.1 \%)$ isolates, respectively (Table 6 ; Figure 1 ). The detection frequency of $p v l$ and sec showed signifi- 
cant difference in isolates from farm B (32.3 and 30.8\%, respectively) than those from farm $\mathrm{A}$ (7.7 and $3.1 \%$, respectively; $P<0.05$; Table 6 ). The enterotoxin genes seb and see were not found in any isolate.

\section{Biofilm-Related Genes and Biofilm Formation Ability}

Of the 13 investigated biofilm-related genes ( $f n b A$, fnbB, clfA, clfB, cna, icaA, sarA, bap, tcaR, ccp, luxS, $\operatorname{agr} C, \operatorname{sig} B), 5$ genes, including $\operatorname{clf} A, \operatorname{clf} B$, cna, sar $A$, and $\operatorname{sig} B$, were found in all $65(100.0 \%)$ isolates. The $f n b A$, fnbB, icaA, luxS, tcaR, and ccp genes were detected in 21 (32.3\%), 23 (35.4\%), 45 (69.2\%), 55 (84.6\%), 56
$(86.2 \%)$, and $62(95.4 \%)$ isolates, respectively (Table 7; Figure 1). The detection frequency of $f n b B$ and $i c a A$ showed a significant difference in isolates from farm $\mathrm{A}$ $(29.2 \%$ and $40.0 \%$, respectively) than those from farm B $(6.2 \%$ and $29.2 \%$, respectively; $P<0.05$; Table 7$)$, and the detection frequency of the luxS gene displayed a significant difference in isolates between farm A $(33.8 \%)$ and farm B $(50.8 \% ; P<0.05$; Table 7$)$.

The microtiter plate assay demonstrated that 64 isolates from the 2 farms could produce biofilm at different intensities (Table 7; Figure 1). Forty isolates $(61.5 \%, 40 / 65)$, including 19 from farm $\mathrm{A}$ and 21 from farm B, were able to produce weak biofilm; 17 strains

Table 2. Clonal distribution of Staphylococcus aureus causing subclinical bovine mastitis in southern Xinjiang, China; CC = clonal complex, $\mathrm{ST}=$ sequence type, MLST $=$ multilocus sequence typing

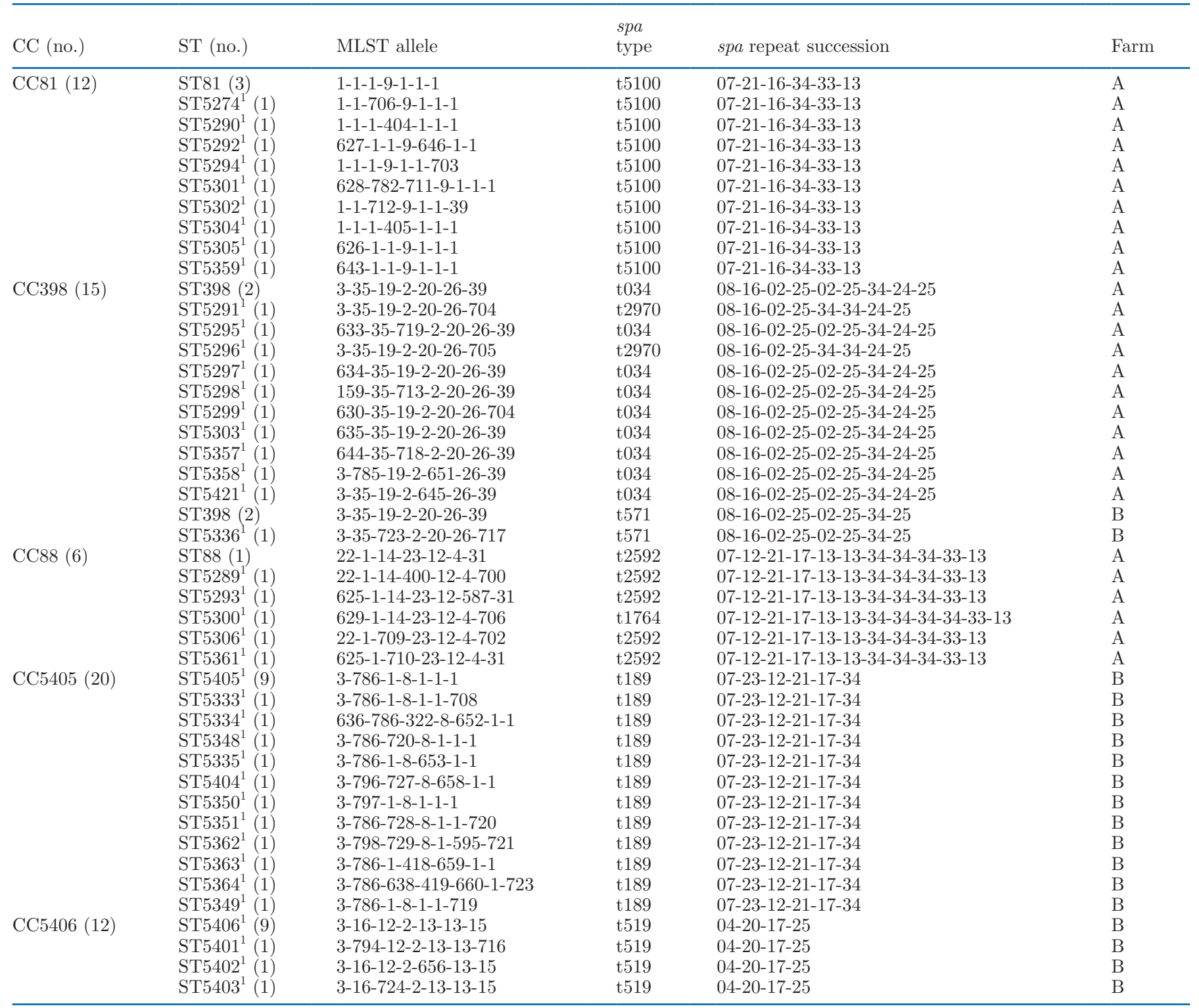

${ }^{1}$ New sequence type found in this study. 
Table 3. Antibiotic resistance of Staphylococcus aureus from subclinical bovine mastitis in dairy farms located in southern Xinjiang, China

\begin{tabular}{llr}
\hline Antibiotic class & Antibiotic & $\begin{array}{c}\text { Strains, } \\
\text { no. }(\%)\end{array}$ \\
\hline B-Lactams & Penicillin G & $38(58.5)$ \\
Glycopeptides & Cefoxitin & $0(0)$ \\
Aminoglycosides & Vancomycin & $0(0)$ \\
Macrolides & Gentamicin & $8(12.3)$ \\
Tetracyclines & Erythromycin & $29(44.6)$ \\
Fluoroquinolones & Tetracycline & $12(18.5)$ \\
& Ciprofloxacin & $3(4.6)$ \\
Lincosamides & Norfloxacin & $3(4.6)$ \\
Folate pathway antagonists & Clindamycin & $26(40.0)$ \\
Phenicols & Sulphamethoxazole-trimethoprim & $0(0)$ \\
Ansamycins & Chloramphenicol & $1(1.5)$ \\
Streptogramins & Rifampicin & $6(9.2)$ \\
Oxazolidomones & Quinupudin-dafupudin & $4(6.2)$ \\
No resistance to antimicrobial agent & Linezolid & $7(10.8)$ \\
Resistant to 1 antimicrobial agent & & $21(32.3)$ \\
Resistant to 2 antimicrobial agents & & $8(12.3)$ \\
Multi-drug resistant & & $9(13.8)$ \\
\hline
\end{tabular}

(26.2\%, 17/65), including 7 isolates from farm $\mathrm{A}$ and 10 from farm B, formed moderate biofilm; and 7 strains $(10.8 \%, 7 / 65)$, including 3 from farm $\mathrm{A}$ and 4 from farm B, could produce strong biofilm.

\section{DISCUSSION}

Contamination of dairy cows and raw milk by $S$. aureus, especially those strains expressing an MDR phenotype and possessing the ability to produce biofilm and toxins, including enterotoxins TSST-1 and PVL, remains an urgent public health issue (Cavicchioli et al., 2015; Wang et al., 2016; Wang et al., 2018). Dairy products contaminated with $S$. aureus have led to foodborne poisoning outbreaks, demonstrating the public health significance of $S$. aureus. Food-borne infections are frequently reported in China in recent years (Rong et al., 2017; Chen and Xie, 2019; Wu et al., 2019a). Additionally, the economic losses to dairy farms are considerable, because dairy cow mastitis results in decreased milk production, increased health care costs, and higher culling rates (Hennekinne et al., 2012). This study investigated the prevalence, genetic diversity, antimicrobial resistance phenotypes, carriage of staphylococcal virulence genes, and capacity of these isolates to form biofilm. All of these S. aureus were isolated from

Table 4. Antimicrobial susceptibility of the study isolates to the 14 antimicrobial agents

\begin{tabular}{|c|c|c|c|c|c|c|c|c|c|}
\hline Antimicrobial $^{1}$ & \multicolumn{3}{|c|}{ Resistant, no. of isolates (\%) } & \multicolumn{3}{|c|}{ Intermediate, no. of isolates (\%) } & \multicolumn{3}{|c|}{ Susceptible, no. of isolates (\%) } \\
\hline FOX & $0(0)$ & $0(0)$ & $0(0)$ & $0(0)$ & $0(0)$ & $0(0)$ & $30(46.2)$ & $35(53.8)$ & 65 (100.0) \\
\hline $\mathrm{TE}$ & $11(16.9)^{*}$ & $1(1.5)$ & $12(18.5)$ & $6(9.2)$ & $5(7.7)$ & $11(16.9)$ & $13(20.0)$ & $29(44.6)$ & $42(64.6)$ \\
\hline $\mathrm{P}$ & $21(32.3)$ & $17(26.2)$ & $38(58.5)$ & $0(0)$ & $0(0)$ & $0(0)$ & $9(13.8)$ & $18(27.7)$ & $27(41.5)$ \\
\hline LZD & $7(10.8)$ & $0(0)$ & $7(10.8)$ & $0(0)$ & $0(0)$ & $0(0)$ & $23(35.4)$ & $35(53.8)$ & $58(89.2)$ \\
\hline CIP & $0(0)$ & $3(4.6)$ & $3(4.6)$ & $2(3.1)$ & $1(1.5)$ & $3(4.6)$ & $28(43.1)$ & $31(47.7)$ & $59(90.8)$ \\
\hline DA & 9 (13.8) & $17(26.2)$ & $26(40.0)$ & $0(0)$ & $0(0)$ & $0(0)$ & $21(32.3)$ & $18(27.7)$ & $39(60.0)$ \\
\hline SXT & $0(0)$ & $0(0)$ & $0(0)$ & $1(1.5)$ & $0(0)$ & $1(1.5)$ & $29(44.6)$ & $35(53.8)$ & $64(98.5)$ \\
\hline NOR & $0(0)$ & $3(4.6)$ & $3(4.6)$ & $0(0)$ & $0(0)$ & $0(0)$ & $30(46.2)$ & $32(49.2)$ & $62(95.4)$ \\
\hline $\mathrm{CN}$ & $6(9.2)$ & $2(3.1)$ & $8(12.3)$ & $0(0)$ & $0(0)$ & $0(0)$ & $24(36.9)$ & $33(50.8)$ & $57(87.7)$ \\
\hline QD & $4(6.2)$ & $0(0)$ & $4(6.2)$ & $6(9.2)$ & $6(9.2)$ & $12(18.5)$ & $20(30.8)$ & $29(44.6)$ & $49(75.4)$ \\
\hline VAN & $0(0)$ & $0(0)$ & $0(0)$ & $0(0)$ & $0(0)$ & $0(0)$ & $30(46.2)$ & $35(53.8)$ & $65(100.0)$ \\
\hline
\end{tabular}

${ }^{1} \mathrm{FOX}=$ cefoxitin; $\mathrm{C}=$ chloramphenicol; $\mathrm{TE}=$ tetracycline; $P=$ penicillin $\mathrm{G} ; \mathrm{LZD}=$ linezolid; $\mathrm{E}=$ erythromycin; $\mathrm{RD}=$ rifampicin; $\mathrm{CIP}=$ ciprofloxacin; DA = clindamycin; SXT = sulfamethoxazole-trimethoprim; NOR = norfloxacin; CN = gentamicin; QD = quinupudin-dafupudin; VAN $=$ vancomycin.

$* P<0.05$. 


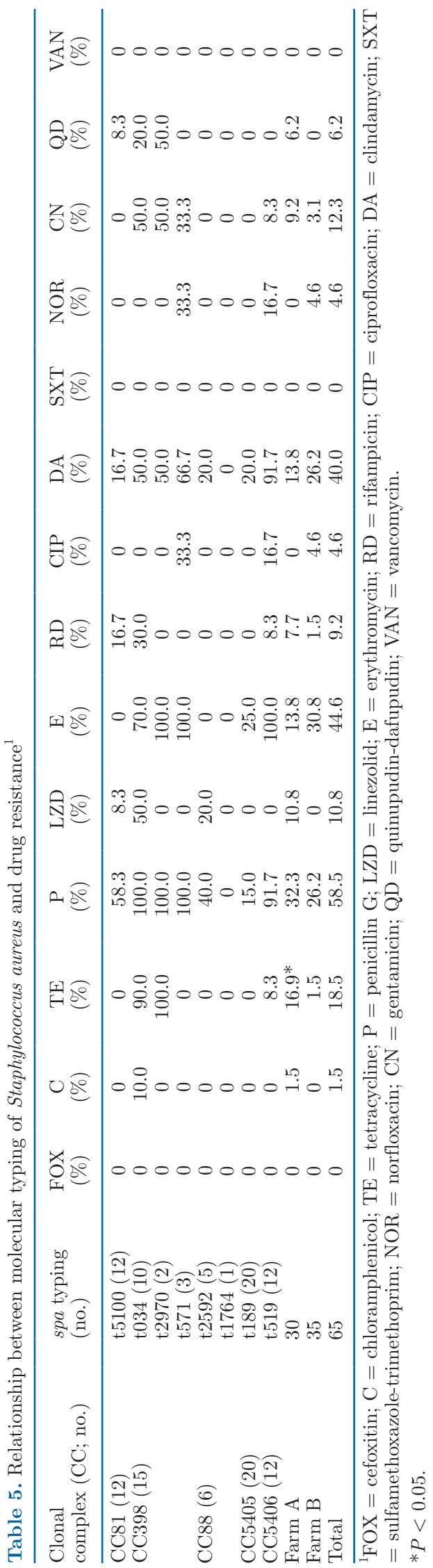

raw milk samples taken from 2 dairy farms in southern Xinjiang, China.

In this study, $S$. aureus isolates displayed the highest rate of resistance to penicillin $(58.5 \%)$. This result is not surprising, because $\beta$-lactams are widely prescribed to treat bovine mastitis cases in China, as well as in Turkey (Aslantaş and Demir, 2016). Previous studies performed in China revealed prevalence of penicillin resistance of $94.3 \%$ in Ningxia, $80.5 \%$ in Shananxi, and $31.3 \%$ in Beijing (Li et al., 2015; Wang et al., 2016; Wang et al., 2018). The erythromycin resistance rate $(44.6 \%)$ found in our study was inconsistent with previous studies conducted by Li et al. (2017) in south China and Wang et al. (2018) in Beijing, who reported resistance rates of 23.6 and $5.2 \%$, respectively. However, $\mathrm{Wu}$ et al. (2019b), Wang et al. (2016), and Liu et al. (2017) reported erythromycin resistance rates as $83.3 \%$ in 39 Chinese cities, $68.6 \%$ in Ningxia, China, and $46.3 \%$ in 4 cities of northern China, respectively. The rate of resistance to tetracycline found in our study (18.5\%) was higher than those found in Beijing by Wang et al. $(2018 ; 1.0 \%)$, in Ningxia by Wang et al. (2016; 5.7\%), and in 4 cities of northern China by Liu et al. (2017; $13.0 \%$ ), but lower than the findings in the Shaanxi Province by $\mathrm{Li}$ et al. $(2015 ; 43.9 \%)$ and in 39 Chinese cities by $\mathrm{Wu}$ et al. (2019b; 65.7\%), suggesting that resistance rates for $S$. aureus, as for other bacteria, vary regionally and are influenced by antimicrobial agent usage. Our results in this study support this, as we found a significant difference in tetracycline resistance between isolates from farm $\mathrm{A}$ and those from farm B $(P$ $<0.05$; Tables 4 and 5).

In recent years, the emergence of MDR S. aureus, particularly MRSA, has become a growing public health concern (Li et al., 2015). Although no MRSA was detected in our study, the rate of MDR phenotype occurrence $(41.5 \%)$ was higher than that reported by $\mathrm{Li}$ et al. $(2017 ; 23.6 \%)$ and Wang et al. $(2018 ; 6.3 \%)$ but lower than that reported by Liu et al. (2017;61.1\%). Methicillin-resistant $S$. aureus is considered a major cause of hospital- and community-acquired infections (Gopal and Divya, 2017; Wang et al., 2018). Recently, the isolation of MRSA from raw milk and dairy products has been reported worldwide (Rola et al., 2016; Basanisi et al., 2017; Wu et al. 2019b). The high prevalence of antimicrobial-resistant $S$. aureus from raw milk, the raw material for dairy products, should be considered a potential risk to human health in southern Xinjiang, China.

With respect to the risk of pathogenicity, the presence of virulence genes among all 65 isolates was also evaluated in this study. Staphylococcal HL have been accepted as important virulence factors that contribute to bacterial invasion and escape from the host immune 
exfoliative hemolysin

staphylococcal enterotoxins genes

biofilm related genes

antimicrobial susceptibility testing

CCs STs spa 离

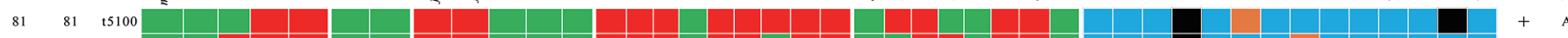

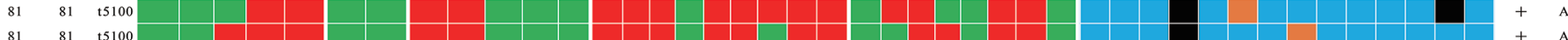

$\begin{array}{lll}81 & 81 & t 5100 \\ 81 & 81 & t 5100\end{array}$

$81 \quad 5274 \quad+5100$

$81 \quad 5290 \quad$ t5100

$81 \quad 5292 \quad \mathrm{t} 5100$

$81 \quad 5294 \quad \mathrm{t} 5100$

$81 \quad 5301 \quad \mathrm{t} 5100$

$81 \quad 5302 \quad t 5100$

$81 \quad 5304 \quad+5100$

$81 \quad 5305 \quad$ t5100

$815359 \quad+5100$

$\begin{array}{lll}398 & 398 & \text { t034 }\end{array}$

$\begin{array}{lll}398 & 398 & \text { t034 }\end{array}$

$\begin{array}{lll}398 & 5295 & \text { t034 }\end{array}$

$398 \quad 5297 \quad$ t034

$\begin{array}{lll}398 & 5298 & \text { t034 }\end{array}$

$\begin{array}{lll}398 & 5299 & \mathrm{t} 034 \\ 398 & 5303 & 1034\end{array}$

$\begin{array}{lll}398 & 5303 & \text { t034 }\end{array}$

$\begin{array}{lll}398 & 5357 & \text { t034 }\end{array}$

$\begin{array}{lll}398 & 5358 & \text { t034 }\end{array}$

$\begin{array}{lll}398 & 5421 & \text { t034 }\end{array}$

$\begin{array}{lll}398 & 5291 \quad \mathrm{t} 2970\end{array}$

$\begin{array}{lll}398 & 5296 \quad \mathrm{t} 2970\end{array}$

$\begin{array}{lll}398 & 5336 & \mathrm{t} 571\end{array}$

$\begin{array}{lll}398 & 398 & \text { t571 }\end{array}$

$\begin{array}{lll}398 & 398 & \mathrm{t} 571\end{array}$

$\begin{array}{lll}88 \quad 88 & \mathrm{t} 2592\end{array}$

$\begin{array}{lll}88 & 5306 & \text { t2592 }\end{array}$

$\begin{array}{lll}88 & 5361 \quad \mathrm{t} 2592\end{array}$

$88 \quad 5300 \quad$ t1764

$\begin{array}{llll}88 & 5293 & \mathrm{t} 2592\end{array}$

$88 \quad 5289 \quad$ t2592

$\begin{array}{lll}5405 & 5333 & \mathrm{t} 189\end{array}$

$\begin{array}{lll}5405 & 5334 & \mathrm{t} 189\end{array}$

$\begin{array}{lll}5405 & 5348 & \mathbf{t} 189\end{array}$

$\begin{array}{lll}5405 & 5335 & \mathrm{t} 189\end{array}$

$\begin{array}{lll}5405 & 5349 & \text { t189 }\end{array}$

$\begin{array}{lll}5405 & 5350 & \text { t189 }\end{array}$

$\begin{array}{lll}5405 & 5351 \quad \mathrm{t} 189\end{array}$

$\begin{array}{lll}5405 & 5362 & \text { t189 }\end{array}$

$\begin{array}{lll}5405 & 5363 \quad t 189\end{array}$

$\begin{array}{lll}5405 & 5404 & 1189\end{array}$

$\begin{array}{lll}5405 & 5364 & \text { t189 }\end{array}$

$\begin{array}{lll}5405 & 5405 & \mathrm{t} 189\end{array}$

$\begin{array}{lll}5405 & 5405 \quad \mathrm{t} 189\end{array}$

$\begin{array}{lll}5405 & 5405 & \mathrm{t} 189\end{array}$

$\begin{array}{lll}5405 & 5405 & \mathrm{t} 189\end{array}$

$\begin{array}{lll}5405 & 5405 \quad \mathrm{t} 189\end{array}$

$\begin{array}{lll}5405 & 5405 \quad \mathrm{t} 189\end{array}$

$\begin{array}{lll}5405 & 5405 & \text { t189 }\end{array}$

$\begin{array}{lll}5405 & 5405 & \text { t189 }\end{array}$

$\begin{array}{lll}5405 & 5405 & \mathrm{t} 189\end{array}$

$\begin{array}{lll}5406 & 5406 \quad \mathrm{t} 519\end{array}$

\begin{tabular}{l}
$5406 \quad 5406 \quad \mathrm{t} 519$ \\
\hline
\end{tabular}

$\begin{array}{lll}5406 & 5406 \quad 1519\end{array}$

$\begin{array}{lll}5406 & 5406 \quad \mathrm{t} 519\end{array}$

$\begin{array}{lll}5406 & 5406 \quad \mathrm{t} 519\end{array}$

$\begin{array}{lll}5406 & 5406 & \text { t519 }\end{array}$

$\begin{array}{lll}5406 & 5406 & \mathrm{t} 519\end{array}$

$\begin{array}{lll}5406 & 5406 & \mathrm{t} 519\end{array}$

$\begin{array}{llll}5406 & 5406 \quad \mathrm{t} 519\end{array}$

$\begin{array}{lll}5406 & 5401 & \text { t519 }\end{array}$

$\begin{array}{lll}5406 & 5402 \quad \mathrm{t} 519\end{array}$

$\begin{array}{lll}5406 & 5403 & \text { t5 }\end{array}$
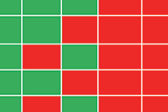

\begin{tabular}{|l|l|l|l|l|l|l|l|l|}
\hline & & & \\
\hline & & & \\
\hline
\end{tabular}
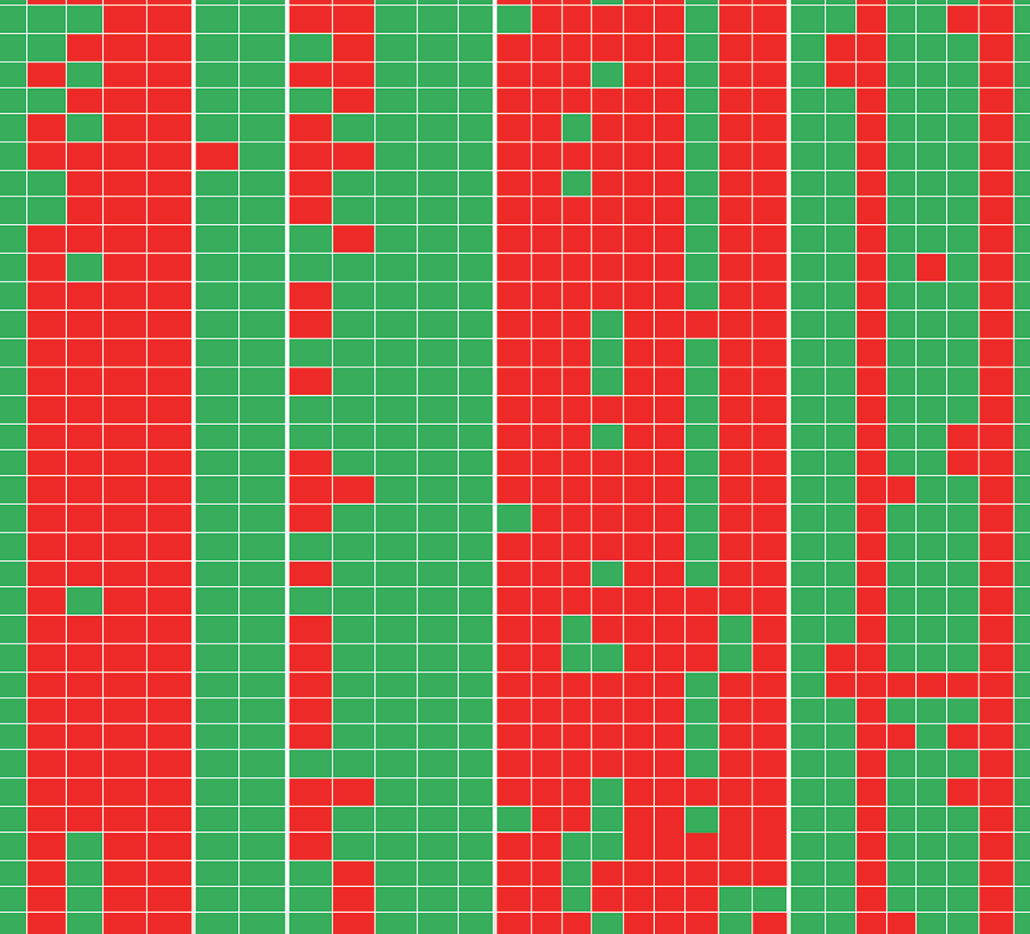

Figure 1. Antimicrobial susceptibility testing (AST), virulence genes, biofilm-related genes and biofilm production, mecA gene, and molecular characterization of 65 Staphylococcus aureus isolates cultured from raw milk in southern Xinjiang, China. Sixty-five isolates were grouped into 5 clonal complexes (CC) and 8 spa types. The results of AST are shown in different colors according to isolates' diameter of inhibition zone in response to different antimicrobial agents. Blue squares indicate susceptibility, brown squares indicate intermediate response, and black squares indicate resistance. The detections of virulence genes, biofilm-related genes and biofilm production, and mecA genes were summarized on a heat map. Green squares denote that the studied genes were detected in those isolates. Red squares denote that those isolates lack the studied genes. $\mathrm{ST}=$ sequence type $\mathrm{BFA}=$ biofilm formation ability. Antimicrobial agents used are abbreviated as follows: $\mathrm{FOX}=$ cefoxitin; $\mathrm{C}=$ chloramphenicol; TE = tetracycline; $\mathrm{P}=$ penicillin $\mathrm{G} ; \mathrm{LZD}=$ linezolid; $\mathrm{E}=$ erythromycin; $\mathrm{RD}=$ rifampicin; $\mathrm{CIP}=$ ciprofloxacin; DA $=$ clindamycin; $\mathrm{SXT}=$ sulphamethoxazole-trimethoprim; NOR = norfloxacin; $\mathrm{CN}=$ gentamicin; QD = quinupudin-dafupudin; VAN = vancomycin. 

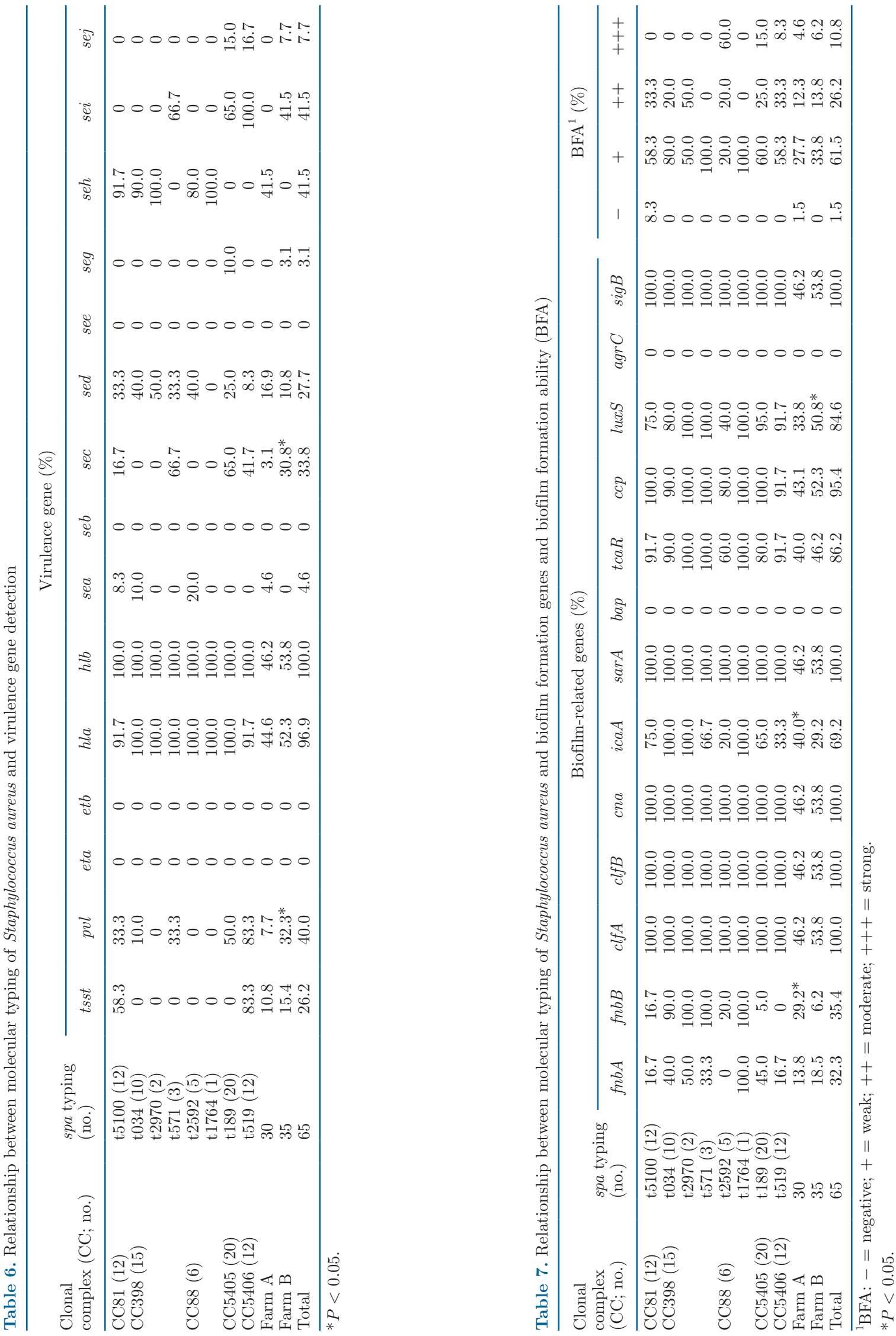
response (Pereyra et al., 2016; Wang et al., 2016). Our study showed that $96.9 \%$ of the total isolates possessed the hla gene, and $100.0 \%$ of strains had the hlb gene, in agreement with previous reports (Wang et al., 2016; Li et al., 2017). Toxic shock syndrome toxin-1 (tsst-1), a superantigen secreted by $S$. aureus in infected hosts, is responsible for toxic shock syndrome in humans (Udo et al., 2016; Wang et al., 2016). Our findings showed that $26.2 \%$ of $S$. aureus isolates harbored the tsst- 1 gene. The prevalence of the tsst-1 gene in our study was higher than that reported by Wang et al. (2018; 2.1\%) and Liu et al. $(2017 ; 14.8 \%)$ but lower than that reported by Wang et al. (2016; 40.0\%). Panton-Valentine leukocidin plays an important role in destroying host leukocytes and results in tissue necrosis (Wang et al., 2018). In the present study, $40.0 \%$ of $S$. aureus isolates had the pvl gene, which was lower than that $(93.8 \%)$ reported in a previous study (Wang et al., 2018) and higher than that reported by Liu et al. (2017; 14.8\%). Interestingly, the prevalence rate of the $p v l$ gene in samples from farm B $(32.3 \%)$ was higher than in those from farm A $(7.7 \% ; P<0.05)$. The classic enterotoxin genes of S. aureus (SE) are known to be responsible for food poisoning incidents. It has been reported that more than $80.0 \%$ of isolates from cow milk related to mastitis carried 1 or more SE genes (Song et al., 2015; Wang et al., 2018). In this study, $95.4 \%$ of isolates harbored SE-encoding genes, and seh and sei (each $41.5 \%$ ) were the most frequently detected enterotoxin genes. This finding is different from those in previous reports from China and Australia (McMillan et al., 2016; Liu et al., 2017; Wang et al., 2018). Additionally, the prevalence rate of the sec gene from farm B $(30.8 \%)$ was higher than that from farm A $(3.1 \% ; P<0.05)$. Therefore, the different prevalence rates of SE genes in $S$. aureus may be attributable to the fact that these isolates originated in geographically diverse locations. According to previous reports, the see gene was rarely present in raw milk or even retail food in China (Liu et al., 2017; Wang et al., 2018), and similarly, this marker was absent in this study.

The biofilm-producing ability of staphylococci has increasingly been considered an important virulence trait. Also, staphylococcal adhesins have been shown to be essential to bind host cells. Therefore, this study also investigated the distribution of biofilm-related and adhesin genes among all isolates. The $f n b A$ gene was detected in $32.3 \%$ of $S$. aureus isolates, which is distinct from the findings of Aslantaş and Demir (2016; 77.7\%), Wang et al. (2016; 94.3\%), and Li et al. (2017; 94.3\%). The prevalence rate of the $f n b B$ gene in our study was $35.4 \%$, which is lower than that reported by Wang et al. $(2016 ; 80.0 \%)$. Additionally, the prevalence rate of the $f n b B$ gene from farm A $(29.2 \%)$ was higher than that from farm B $(6.2 \% ; P<0.05)$. The clfA gene was detected in all 65 isolates, which is consistent with a previous study conducted by Li et al. (2017) in southern China. In contrast, the bap and $\arg C$ genes were absent in all 65 isolates. The prevalence rate of the $i c a A$ gene from farm A (40.0\%) was higher than that from farm B $(29.2 \% ; P<0.05)$, whereas the prevalence rate of the luxS gene from farm B (50.8\%) was higher than that from farm A $(33.8 \% ; P<0.05)$. The different prevalence rates of these genes in $S$. aureus could be attributable to the fact that these tested isolates originated in geographically diverse locations. In the present study, 64 isolates could form biofilms, as measured by the microtiter plate assay described above, and these findings agree with a previous study conducted in Beijing (Wang et al., 2018). The high incidence of biofilmforming $S$. aureus isolates in these studies suggests the necessity for dairy farms to improve quality-assurance systems, to decrease and eliminate these isolates (Wang et al., 2018).

Our data also highlighted the genetic diversity of the $S$. aureus isolates from subclinical mastitis, through MLST and spa typing. In the present study, the $65 S$. aureus isolates from 2 geographic regions in southern Xinjiang, China, were grouped into $44 \mathrm{ST}$ and 8 spa types. Importantly, analysis of the isolates in this study identified 41 novel ST not previously reported (Table 2 ; Figure 2). The goeBURST algorithm was used to examine the population structure of isolates in our study relative to global bovine isolates. The global population structure of bovine milk-associated $S$. aureus ST formed 14 primary groups (McMillan et al., 2016). With the exception of ST5405 and ST5406, bovine isolates from this study were representative of the predicted founding ST of their associated group or CC. Twelve of the bovine isolates from this study fell into CC81, 15 into CC398, 6 into CC88, 20 into CC5405, and 12 into CC5406. The isolates ST5405 and ST5406 have emerged as dominant lineages derived from bovine milk in this study, which is distinct from findings of Hata et al. (2010) and McMillan et al. (2016).

\section{CONCLUSIONS}

Our study demonstrated that $S$. aureus isolates of subclinical bovine mastitis in southern Xinjiang, China, widely harbored both biofilm-related and enterotoxin genes involved in the pathogenesis of $S$. aureus infections, which indicate potential virulence of the isolates. Additionally, high levels of resistance against $\beta$-lactams and erythromycin, which are widely used in veterinary practice, were observed in this study. More importantly, a high percentage of MDR was present in this study, so the pathogenicity and transmission 


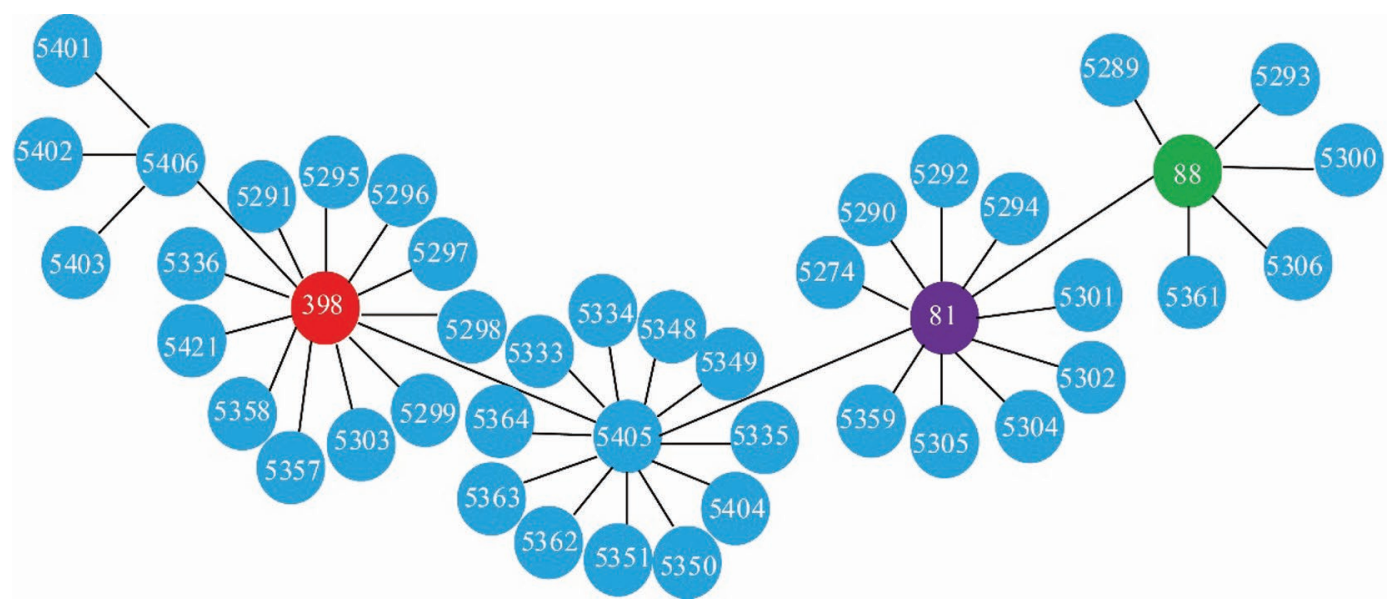

Figure 2. goeBURST diagram for the multilocus sequence typing (MLST) data of 65 Staphylococcus aureus isolates. The goeBURST diagram was calculated using PHYLOViZ with the goeBURST algorithm (http://goeBURST.phyloviz.net). Sequence types (ST) were grouped according to their allelic profiles. All 44 ST are represented by filled circles. Each filled circle represents a unique ST. Central circles represent ST that are group founders of MLST clonal complexes. All other ST are single-locus variants or multi-loci variants. Light blue circles represent new ST identified in this study.

risk of $S$. aureus cannot be ignored. Notably, it is essential to control and eliminate the presence of MDR, enterotoxigenic, and biofilm-forming $S$. aureus in raw milk. Also, our study showed the genetic diversity of these isolates. Forty-one new ST were detected for the first time. Significant differences in genetic diversity, along with antibiotic resistance and biofilm formation, were observed for $S$. aureus isolates from subclinical mastitis. Our study showed that $S$. aureus strains with similar genetic characteristics exhibited specific antibiotic resistance patterns, virulence gene profiles, and biofilm formation abilities. Therefore, monitoring the genotypes of $S$. aureus in dairy herds would help distinguish prevalant clones, to develop control strategies for mastitis caused by $S$. aureus.

\section{ACKNOWLEDGMENTS}

This work was supported by the Program for New Century Excellent Talents in University (grant number NCET-11-1071) of China (Beijing), National Science Foundation of China (Beijing) Grant No. 31260026, and the Program for Young and Middle-Aged Technology Innovation Leading Talents (2019CB029; Urumqi, China). W. Chen is supported by PhD funding in the Xinjiang Production and Construction Corps (2009JC07; Urumqi, China) and Joint Fund of Nanjing Agricultural University and Tarim University (NNLH201901; Alar, China); Q. Ren is supported by the Postgraduate Student Research and Innovation Project of Tarim University (TDGRI201811; Alar, China); and Z. Wu is supported by the National Training Program of Innovation and Entrepreneurship for Undergraduates
(201910757025; Alar, China). The authors declare that they have no competing interest.

\section{REFERENCES}

Arciola, C. R.. L. Baldassarri, and L. Montanaro. 2001. Presence of $i c a A$ and $i c a D$ genes and slime production in a collection of staphylococcal strains from catheter-associated infections. J. Clin. Microbiol. 39:2151-2156. https://doi.org/10.1128/JCM.39.6.2151 $-2156.2001$.

Arfatahery, N., A. Davoodabadi, and T. Abedimohtasab. 2016. Characterization of toxin genes and antimicrobial susceptibility of Staphylococcus aureus isolates in fishery products in Iran. Sci. Rep. 6:34216. https://doi.org/10.1038/srep34216.

Aslantas, Ö., and C. Demir. 2016. Investigation of the antibiotic resistance and biofilm-forming ability of Staphylococcus aureus from subclinical bovine mastitis cases. J. Dairy Sci. 99:8607-8613. https: //doi.org/10.3168/jds.2016-11310.

Atalla, H., C. Gyles, C. L. Jacob, H. Moisan, F. Malouin, and B. Mallard. 2008. Characterization of a Staphylococcus aureus small colony variant (SCV) associated with persistent bovine mastitis. Foodborne Pathog. Dis. 5:785-799. https://doi.org/10.1089/fpd .2008 .0110 .

Basanisi, M. G., G. La Bella, G. Nobili, I. Franconieri, and G. La Salandra. 2017. Genotyping of methicillin-resistant Staphylococcus aureus (MRSA) isolated from milk and dairy products in South Italy. Food Microbiol. 62:141-146. https://doi.org/10.1016/j.fm .2016.10.020.

Brakstad, O. G., K. Aasbakk, and J. A. Maeland. 1992. Detection of Staphylococcus aureus by polymerase chain reaction amplification of the nuc gene. J. Clin. Microbiol. 30:1654-1660.

Cavicchioli, V. Q., T. M. Scatamburlo, A. K. Yamazi, F. A. Pieri, and L. A. Nero. 2015. Occurrence of Salmonella, Listeria monocytogenes, and enterotoxigenic Staphylococcus in goat milk from small and medium-sized farms located in Minas Gerais State, Brazil. J. Dairy. Sci. 98:8386-8390. https://doi.org/10.3168/jds.2015-9733.

Chen, Q., and S. Xie. 2019. Genotypes, enterotoxin gene profiles, and antimicrobial resistance of Staphylococcus aureus associated with foodborne outbreaks in Hangzhou, China. Toxins (Basel) 11:307. https://doi.org/10.3390/toxins11060307.

Ciftci, A., A. Findik, E. E. Onuk, and S. Savasan. 2009. Detection of methicillin resistance and slime factor production of Staphylo- 
coccus aureus in bovine mastitis. Braz. J. Microbiol. 40:254-261. https://doi.org/10.1590/S1517-83822009000200009.

CLSI. (2015). Methods for antimicrobial dilution and disk susceptibility testing of infrequently isolated or fastidious bacteria: Approved guideline. Clinical Laboratory Standards Institute, Wayne, PA.

Felipe, V., C. A. Morgante, P. S. Somale, F. Varroni, M. L. Zingaretti, R. A. Bachetti, S. G. Correa, and C. Porporatto. 2017. Evaluation of the biofilm forming ability and its associated genes in Staphylococcus species isolates from bovine mastitis in Argentinean dairy farms. Microb. Pathog. 104:278-286. https://doi.org/10.1016/j .micpath.2017.01.047.

Gomes, F., and M. Henriques. 2016. Control of bovine mastitis: Old and recent therapeutic approaches. Curr. Microbiol. 72:377-382. https://doi.org/10.1007/s00284-015-0958-8.

Gopal, S., and K. C. Divya. 2017. Can methicillin-resistant Staphylococcus aureus prevalence from dairy cows in India act as potential risk for community-associated infections? A review. Vet World 10:311-318. https://doi.org/10.14202/vetworld.2017.311-318.

Hata, E., K. Katsuda, H. Kobayashi, I. Uchida, K. Tanaka, and M. Eguchi. 2010. Genetic variation among Staphylococcus aureus strains from bovine milk and their relevance to methicillin-resistant isolates from humans. J. Clin. Microbiol. 48:2130-2139. https: //doi.org/10.1128/JCM.01940-09.

Haveri, M., M. Hovinen, A. Roslöf, and S. Pyörälä. 2008. Molecular types and genetic profiles of Staphylococcus aureus strains isolated from bovine intramammary infections and extramammary sites. J. Clin. Microbiol. 46:3728-3735. https://doi.org/10.1128/JCM .00769-08.

Hennekinne, J. A., M. L. De Buyser, and S. Dragacci. 2012. Staphylococcus aureus and its food poisoning toxins: Characterization and outbreak investigation. FEMS Microbiol. Rev. 36:815-836. https:/ /doi.org/10.1111/j.1574-6976.2011.00311.x.

Hertl, J. A., Y. T. Gröhn, J. D. G. Leach, D. Bar, G. J. Bennett, R. N. González, B. J. Rauch, F. L. Welcome, L. W. Tauer, and Y. H. Schukken. 2010. Effects of clinical mastitis caused by grampositive and gram-negative bacteria and other organisms on the probability of conception in New York state Holstein dairy cows. J. Dairy Sci. 93:1551-1560. https://doi.org/10.3168/jds.2009-2599.

Jakobsen, R. A., R. Heggeb $\varnothing$, E. B. Sunde, and M. Skjervheim. 2011. Staphylococcus aureus and Listeria monocytogenes in Norwegian raw milk cheese production. Food Microbiol. 28:492-496. https:// doi.org/10.1016/j.fm.2010.10.017.

Käppeli, N., M. Morach, S. Corti, C. Eicher, R. Stephan, and S. Johler. 2019. Staphylococcus aureus related to bovine mastitis in Switzerland: Clonal diversity, virulence gene profiles, and antimicrobial resistance of isolates collected throughout 2017. J. Dairy Sci. 102:3274-3281. https://doi.org/10.3168/jds.2018-15317.

Kateete, D. P., U. Kabugo, H. Baluku, L. Nyakarahuka, S. Kyobe, M. Okee, C. F. Najjuka, and M. L. Joloba. 2013. Prevalence and antimicrobial susceptibility patterns of bacteria from milkmen and cows with clinical mastitis in and around Kampala, Uganda. PLoS One 8:e63413. https://doi.org/10.1371/journal.pone.0063413.

Khoramian, B., F. Jabalameli, A. Niasari-Naslaji, M. Taherikalani, and M. Emaneini. 2015. Comparison of virulence factors and biofilm formation among Staphylococcus aureus strains isolated from human and bovine infections. Microb. Pathog. 88:73-77. https:// doi.org/10.1016/j.micpath.2015.08.007.

Klein, R. C., M. H. Fabres-Klein, M. A. Brito, L. G. Fietto, and A. O. Ribon. 2012. Staphylococcus aureus of bovine origin: Genetic diversity, prevalence and the expression of adhesin-encoding genes. Vet. Microbiol. 160:183-188. https://doi.org/10.1016/j.vetmic.2012.05 .025 .

Lauderdale, K. J., B. R. Boles, A. L. Cheung, and A. R. Horswill. 2009. Interconnections between Sigma B, agr, and proteolytic activity in Staphylococcus aureus biofilm maturation. Infect. Immun. 77:1623-1635. https://doi.org/10.1128/IAI.01036-08.

Li, L., L. Zhou, L. Wang, H. Xue, and X. Zhao. 2015. Characterization of methicillin-resistant and -susceptible staphylococcal isolates from bovine milk in northwestern China. PLoS ONE 10:e0116699. https://doi.org/10.1371/journal.pone.0116699.
Li, T., H. Lu, X. Wang, Q. Gao, Y. Dai, J. Shang, and M. Li. 2017. Molecular characteristics of Staphylococcus aureus causing bovine mastitis between 2014 and 2015. Front. Cell. Infect. Microbiol. 7:127. https://doi.org/10.3389/fcimb.2017.00127.

Li, X., F. Fang, J. Zhao, N. Lou, C. Li, T. Huang, and Y. Li. 2018. Molecular characteristics and virulence gene profiles of Staphylococcus aureus causing bloodstream infection. Braz. J. Infect. Dis. 22:487-494. https://doi.org/http://dx.doi.org/10.1016/j.bjid.2018 .12 .001 .

Liu, H., S. Li, L. Meng, L. Dong, S. Zhao, X. Lan, J. Wang, and N. Zheng. 2017. Prevalence, antimicrobial susceptibility, and molecular characterization of Staphylococcus aureus isolated from dairy herds in northern China. J. Dairy Sci. 100:8796-8803. https://doi .org/10.3168/jds.2017-13370.

Løvseth, A., S. Loncarevic, and K. G. Berdal. 2004. Modified multiplex PCR method for detection of pyrogenic exotoxin genes in staphylococcal isolates. J. Clin. Microbiol. 42:3869-3872. https:// doi.org/10.1128/JCM.42.8.3869-3872.2004.

McMillan, K., S. C. Moore, C. M. McAuley, N. Fegan, and E. M. Fox. 2016. Characterization of Staphylococcus aureus isolates from raw milk sources in Victoria, Australia. BMC Microbiol. 16:169. https: //doi.org/10.1186/s12866-016-0789-1.

Montanaro, L., S. Ravaioli, W. Ruppitsch, D. Campoccia, G. Pietrocola, L. Visai, P. Speziale, F. Allerberger, and C. R. Arciola. 2016. Molecular characterization of a prevalent ribocluster of methicillinsensitive Staphylococcus aureus from orthopedic implant infections. Correspondence with MLST CC30. Front. Cell. Infect. Microbiol. 6:8. https://doi.org/10.3389/fcimb.2016.00008.

Panahi, M., and H. D. Saei. 2019. Genetic diversity and methicillin resistance of Staphylococcus aureus originating from buffaloes with mastitis in Iran. Comp. Immunol. Microbiol. Infect. Dis. 62:19-24. https://doi.org/http://dx.doi.org/10.1016/j.cimid.2018.11.014.

Pereyra, E. A., F. Picech, M. S. Renna, C. Baravalle, C. S. Andreotti, R. Russi, L. F. Calvinho, C. Diez, and B. E. Dallard. 2016. Detection of Staphylococcus aureus adhesion and biofilm-producing genes and their expression during internalization in bovine mammary epithelial cells. Vet. Microbiol. 183:69-77. https://doi.org/10 .1016/j.vetmic.2015.12.002.

Pratt, L. A., and R. Kolter. 1998. Genetic analysis of Escherichia coli biofilm formation: Roles of flagella, motility, chemotaxis and type I pili. Mol. Microbiol. 30:285-293. https://doi.org/10.1046/j.1365 $-2958.1998 .01061 . x$.

Rola, J. G., A. Czubkowska, W. Korpysa-Dzirba, and J. Osek. 2016. Occurrence of Staphylococcus aureus on farms with small scale production of raw milk cheeses in Poland. Toxins (Basel) 8:62. https: //doi.org/10.3390/toxins8030062.

Rong, D., Q. Wu, M. Xu, J. Zhang, and S. Yu. 2017. Prevalence, virulence genes, antimicrobial susceptibility, and genetic diversity of Staphylococcus aureus from retail aquatic products in China. Front. Microbiol. 8:714. https://doi.org/http://dx.doi.org/10 $.3389 /$ fmicb.2017.00714.

Sato'o, Y., K. Omoe, I. Naito, H. K. Ono, A. Nakane, M. Sugai, N. Yamagishi, and D. L. Hu. 2014. Molecular epidemiology and identification of a Staphylococcus aureus clone causing food poisoning outbreaks in Japan. J. Clin. Microbiol. 52:2637-2640. https://doi .org/10.1128/JCM.00661-14.

Schroeder, J. W. 2012. Bovine Mastitis and Milking Management. North Dakota State University. Accessed Mar. 1, 2018. http:// www.clemson.edu/extension/ scaged/scffa/career-developmentevents/files/dairy-evaluation/mastitiscontrol-programs.pdf.

Shopsin, B., M. Gomez, S. O. Montgomery, D. H. Smith, M. Waddington, D. E. Dodge, D. A. Bost, M. Riehman, S. Naidich, and B. N. Kreiswirth. 1999. Evaluation of protein A gene polymorphic region DNA sequencing for typing of Staphylococcus aureus strains. J. Clin. Microbiol. 37:3556-3563.

Song, M., Y. Bai, J. Xu, M. Q. Carter, C. Shi, and X. Shi. 2015. Genetic diversity and virulence potential of Staphylococcus aureus isolates from raw and processed food commodities in Shanghai. Int. J. Food Microbiol. 195:1-8. https://doi.org/10.1016/j.ijfoodmicro .2014.11.020. 
Sun, L., Y. Chen, D. Wang, H. Wang, D. Wu, K. Shi, P. Yan, and Y. Yu. 2019. Surgical site infections caused by highly virulent methicillin-resistant Staphylococcus aureus sequence type 398, China. Emerg. Infect. Dis. 25:157-160. https://doi.org/10.3201/eid2501 .171862 .

Tarekgne, E. K., T. Skjerdal, S. Skeie, K. Rudi, D. Porcellato, B. Félix, and J. A. Narvhus. 2016. Enterotoxin gene profile and molecular characterization of Staphylococcus aureus isolates from bovine bulk milk and milk products of Tigray region, Northern Ethiopia. J. Food Prot. 79:1387-1395. https://doi.org/10.4315/0362-028X.JFP $-16-003$.

Udo, E. E., S. S. Boswihi, and N. Al-Sweih. 2016. High prevalence of toxic shock syndrome toxin-producing epidemic methicillinresistant Staphylococcus aureus 15 (EMRSA-15) strains in Kuwait hospitals. New Microbes New Infect. 12:24-30. https://doi.org/10 .1016/j.nmni.2016.03.008.

Wang, D., L. Zhang, X. Zhou, Y. He, C. Yong, M. Shen, O. Szenci, and B. Han. 2016. Antimicrobial susceptibility, virulence genes, and randomly amplified polymorphic DNA analysis of Staphylococcus aureus recovered from bovine mastitis in Ningxia, China. J. Dairy Sci. 99:9560-9569. https://doi.org/10.3168/jds.2016-11625.

Wang, W., X. Lin, T. Jiang, Z. Peng, J. Xu, L. Yi, F. Li, S. Fanning, and Z. Baloch. 2018. Prevalence and characterization of Staphylococcus aureus cultured from raw milk taken from dairy cows with mastitis in Beijing, China. Front. Microbiol. 9:1123. https://doi .org/10.3389/fmicb.2018.01123.

Wu, S., J. Huang, F. Zhang, Q. Wu, J. Zhang, R. Pang, H. Zeng, X. Yang, M. Chen, J. Wang, J. Dai, L. Xue, T. Lei, and X. Wei. 2019b. Prevalence and characterization of food-related methicillinresistant Staphylococcus aureus (MRSA) in China. Front. Microbiol. 10:304. https://doi.org/10.3389/fmicb.2019.00304.

Wu, S., F. Zhang, J. Huang, Q. Wu, J. Zhang, J. Dai, H. Zeng, X. Yang, M. Chen, R. Pang, T. Lei, Y. Zhang, L. Xue, J. Wang, and Y. Ding. 2019a. Phenotypic and genotypic characterization of PVL-positive Staphylococcus aureus isolated from retail foods in China. Int. J. Food Microbiol. 304:119-126. https://doi.org/10 .1016/j.ijfoodmicro.2019.05.021.

Xie, T. T., H. Zeng, X. P. Ren, N. Wang, Z. J. Chen, Y. Zhang, and W. Chen. 2019. Antibiofilm activity of three Actinomycete strains against Staphylococcus epidermidis. Lett. Appl. Microbiol. 68:7380. https://doi.org/10.1111/lam.13087.

Zmantar, T., K. Chaieb, H. Makni, H. Miladi, F. B. Abdallah, K. Mahdouani, and A. Bakhrouf. 2008. Detection by PCR of adhesins genes and slime production in clinical Staphylococcus aureus. J. Basic Microbiol. 48:308-314. https://doi.org/10.1002/jobm 200700289 .

\section{ORCIDS}

Qiang Ren @ https://orcid.org/0000-0001-6323-6465

Guanghua Liao 으 https://orcid.org/0000-0002-3895-0621

Zihao Wu • https://orcid.org/0000-0002-0241-1220

Junfan Lv @ https://orcid.org/0000-0002-5937-9751

Wei Chen (๑) https://orcid.org/0000-0002-3761-1572 